\title{
Dimensions of Perfectionism and Constructive Thinking as a Coping Response
}

\author{
Gordon L. Flett
}

York University

\section{Frank A. Russo}

Queen's University

\section{Paul L. Hewitt}

University of British Colombia

$\underline{\text { digital.library.ryerson.ca/object/363 }}$

Please Cite:

Flett, G. L., Russo, F. A., \& Hewitt, P. L. (1994). Dimensions of perfectionism and constructive thinking as a coping response. Journal of Rational-Emotive and Cognitive-Behavior Therapy, 12(3), 163-179.

doi:10.1007/BF02354594

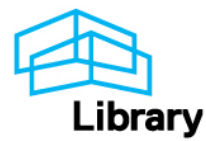




\title{
DIMENSIONS OF PERFECTIONISM AND CONSTRUCTIVE THINKING AS A COPING RESPONSE
}

\author{
Gordon L. Flett \\ York University \\ Frank A. Russo \\ Queen's University \\ Paul L. Hewitt \\ University of British Columbia
}

ABSTRACT: The present study examined perfectionism and general coping ability as assessed by a new measure of constructive thinking. A sample of 77 students completed the Multidimensional Perfectionism Scale (MPS) and the Constructive Thinking Inventory (CTI). The MPS provides measures of selforiented, other-oriented, and socially prescribed perfectionism, while the CTI provides various measures, including summary scores of global constructive thinking, emotional coping, behavioral coping, categorical thinking, personal superstitious thinking, naive optimism, and esoteric thinking. Subjects also completed a measure of depressive symptoms so that we could examine perfectionism and coping independent of current levels of adjustment. The main finding was that socially prescribed perfectionism was associated with less constructive thinking and more negative coping across most of the CTI subscales, and these associations remained significant after removing variance due to levels of depression symptoms. Self-oriented perfectionism was adaptive in that it was associated with active forms of behavioral coping, but it was maladaptive in that it was associated with a form of emotional coping involving reduced self-acceptance. The results are discussed in terms of their implications for the cognitive treatment of perfectionists.

KEY WORDS: perfectionism, coping, depression, maladaptive cognitions.

This research was supported by grant \#410-91-0856 from the Social Sciences and Humanities Research Council of Canada awarded to the authors.

Requests for reprints should be adddressed to Gordon L. Flett, Department of Psychology, York University, 4700 Keele Street, North York, Ontario, Canada, M3J 1 P3. 
In recent years, there have been several noteworthy advances in the understanding of the perfectionism construct. First, it has been established that the perfectionism is a personality trait that is present at an early age in children. Stable individual differences in perfectionism among children have been detected (Flett, Hewitt, Boucher, Davidson, \& Munro, 1992). Second, research has demonstrated the multidimensional nature of the perfectionism construct. Whereas past research focused on the self-oriented aspects of perfectionism by focusing exclusively on personal standards (e.g., Burns, 1980; Pirot, 1986), more recent work (e.g., Hewitt \& Flett, 1990, 1991b) has included an emphasis on both the personal and interpersonal aspects of perfectionism by including a focus on other-oriented perfectionism (i.e., high standards for others) and socially prescribed perfectionism (i.e., the belief that others demand perfection). Third, and finally, the broad association between perfectionism and maladjustment has been demonstrated through research that examines perfectionism and such negative outcomes as anxiety, depression, and suicide, as well as personality disorders and related symptoms (Flett, Hewitt, Blankstein, \& Mosher, 1991; Flett, Hewitt, Blankstein, \& O’Brien, 1991; Frost, Marten, Lahart, \& Rosenblate, 1990; Frost, Heimberg, Holt, Mattia, \& Neubauer, 1993; Frost \& Shows, 1993; Hewitt \& Flett, 1991a, 1991b, 1993a, 1993b; Hewitt, Flett, \& Weber, in press; Rickner \& Tan, 1994).

Consistent with the latter theme, the purpose of the present research is to examine the association between dimensions of perfectionism and coping tendencies. The general premise behind this work is that perfectionism is a construct that is associated broadly with the adjustment process. That is, not only is perfectionism linked directly with negative outcomes such as anxiety and depression, perfectionism is also associated with the particular manner in which individuals attempt to cope with their daily problems and attendant feelings of distress. This possibility is consistent with the general association between personality traits and coping (see Hewitt \& Flett, in press).

The main hypothesis of the present study is that the dimension known as socially prescribed perfectionism is associated with a maladaptive coping orientation. Individuals with high levels of socially prescribed perfectionism perceive that they are exposed to a situation of overcontrol that results in a great deal of punishment for the self. Socially prescribed perfectionism incorporates elements of helplessness and hopelessness in that it is impossible to meet prescribed standards of perfectionism and win the approval of significant others, and any approximation of perfect behavior will result in the standard be- 
ing raised even higher. The observation that socially prescribed perfectionism is associated with motivational deficits has important implications for the coping process. A program of research by Dweck and associates on motivational styles has drawn an important distinction between a mastery orientation and a helplessness orientation (see Dweck, 1986; Dweck \& Elliott, 1983; Dweck \& Leggett, 1988; Elliott \& Dweck, 1988). Individuals with a mastery orientation tend to persist when they are confronted with a challenging situation or problem. These individuals continue to engage in problem-solving and cope with problems in a task-focused manner until a solution has been reached (Dweck \& Leggett, 1988; Elliott \& Dweck, 1988). In contrast, individuals with a helplessness orientation do not respond well when challenged by life difficulties. The predominant response of an individual with a helplessness orientation is to give up when confronted with difficult problems and reflect on personal inadequacies in an emotionfocused manner (Dweck \& Leggett, 1988). Because socially prescribed perfectionism incorporates an element of helplessness at a dispositional level, it follows that people with a high level of socially prescribed perfectionism should exhibit a wide range of maladaptive coping responses.

General support for a link between perfectionism and coping tendencies has been provided in separate studies in our laboratory. Flett, Hewitt, Blankstein, and O'Brien (1991) examined the link between dimensions of perfectionism and learned resourcefulness, as assessed by a measure of self-control. Flett et al. (1991) found that socially prescribed perfectionism was not correlated significantly with resourcefulness, but regression analyses indicated that the combination of socially prescribed perfectionism and low personal resourcefulness was associated with higher levels of depression. In contrast, both self-oriented and other-oriented perfectionism were associated with higher levels of self-control. This finding is consistent with other data indicating that self-oriented perfectionism may have an adaptive component (Frost, Holt, Heimberg, Mattia, \& Neubauer, 1993), in part due to the intrinsic motivation and persistence that is inherent in self-oriented perfectionism.

Other research indicates that self-oriented perfectionism may be associated jointly with positive and negative coping tendencies, while socially prescribed perfectionism is associated entirely with negative component tendencies. Hewitt, Flett, and Endler (in press) examined dimensions of perfectionism and coping in a sample of 53 male and 67 female psychiatric patients. Self-oriented perfectionism was associated 
with higher levels of adaptive, task-oriented coping in men and women, but it was also associated with maladaptive, emotion-oriented coping in women. There were no significant correlations involving other-oriented perfectionism. In contrast, socially prescribed perfectionism was associated with an absence of social diversion in women and the presence of emotion-focused coping in men. Finally, Flett, Hewitt, Blankstein, Solnik, and Van Brunschot (1994) examined perfectionism and perceived problem-solving ability in samples of college students. The primary finding of this research was that socially prescribed perfectionism was associated with poorer appraisals of problem-solving ability, and this link remained presented even after removing variance due to current levels of negative affect. Flett et al. (1994) interpreted these data as providing support for the general view that socially prescribed perfectionism involves a helplessness orientation.

The primary purpose of the present research was to expand the literature on perfectionism and coping by examining the association between the perfectionism dimensions and the indices derived from the Constructive Thinking Inventory (Epstein \& Meier, 1989). Epstein (1992) has suggested that poor constructive thinkers, as assessed by his Constructive Thinking Inventory, suffer from the helplessness pattern identified by Dweck and her associates. In experimental research, Epstein and colleagues have confirmed that poor constructive thinkers respond poorly when confronted with a difficult situation and they tend to exhibit many of the characteristics associated with a helplessness orientation, including increased levels of negative affect, and negative self-judgments involving blame and overgeneralization (Epstein, 1992; Katz \& Epstein, 1991). Given that scores on the Constructive Thinking Inventory are related to a helplessness orientation, it should be the case that socially prescribed perfectionists suffer from a relative absence of constructive thinking when in coping situations. This possibility was the main hypothesis of the current study.

In addition to providing a means of re-examining the general link between perfectionism and coping, the Constructive Thinking Inventory is an informative measure in the present context because it may be used to shed light on the cognitive tendencies of perfectionists. The Constructive Thinking Inventory is a unique measure that assesses a wide variety of dysfunctional thinking tendencies. Past descriptions of perfectionists have indicated that they exhibit many of the cognitive tendencies that Beck (1976) has associated with depression; that is, perfectionists have been described as engaging in selective attention 
to and overgeneralization of failure, and a tendency to engage in allor-none thinking whereby only total success or total failure exist as outcomes (Barrow \& Moore, 1983; Burns, 1980; Hamachek, 1978; Hollender, 1965; Pacht, 1984). These negative cognitive characteristics are believed to stem, in part, from the cognitive operations inherent in the ideal self-schema (see Hewitt \& Genest, 1990). Although the negative cognitive tendencies of perfectionists have been discussed widely, there have been few empirical attempts to confirm a link between perfectionism and negative cognitive operations. The primary exception is research with subclinical and clinical subjects which suggests a tendency for perfectionists to engage in the overgeneralization of failure to all aspects of the self (Hewitt, Flett, Turnbull-Donovan, \& Mikail, 1991; Hewitt, Mittelstaedt, \& Wollert, 1989). Related investigations indicate that there is a link between perfectionism and cognitive concern about making mistakes (Frost \& Henderson, 1991), and some research has established an association between dimensions of perfectionism and core irrational beliefs (Flett, Hewitt, Blankstein, \& Koledin, 1991). The CTI is a useful means of further examining the link between perfectionism and cognitive tendencies because it provides self-report measures of categorical thinking, superstitious thinking, stereotypical thinking, and overgeneralization, as well as more adaptive forms of positive thinking.

To reiterate, then, the main purpose of the present study was to further investigate the link between dimensions of perfectionism and aspects of coping as operationalized by the CTI. Given the content of the CTI, a related goal was to examine the cognitive tendencies of perfectionists. Consistent with existing data on perfectionism and coping styles, as well as the growing body of literature on the adjustment problems of people with elevated levels of socially prescribed perfectionism, we predicted that socially prescribed perfectionism would be associated with a general absence of constructive thinking across the various CTI subscales. This pattern would be in keeping with earlier suggestions that people with high levels of socially prescribed perfectionism suffer from motivational deficits that exist in conjunction with numerous irrational beliefs (Flett, Hewitt, Blankstein, \& Koledin, 1991; Flett, Hewitt, McGregor-Temple, \& Pickering, 1994). Specific hypotheses were not put forth for the link between other-oriented perfectionism and dimensions of constructive thinking. Finally, we hypothesized that self-oriented perfectionism would be associated generally with reports of more adaptive coping tendencies since this dimension incorporates a mastery orientation. However, given the 
tendency for self-oriented perfectionists to be high in levels of selfcriticism (Hewitt \& Flett, 1993a), we also predicted that self-oriented perfectionism would be associated negatively with the CTI measure of positive thinking that involved thoughts of self-acceptance.

In addition to completing measures of perfectionism and constructive thinking, subjects in this study also completed a measure of depressive symptomatology. Inclusion of a depression measure enabled us to obtain further information about the link between the CTI subscales and personal adjustment, and it allowed us to test the replicability of previous findings indicating a negative association between constructive thinking and emotional adjustment problems (Epstein \& Katz, 1992; Epstein \& Meier, 1989). Past research has indicated that the three broad measures derived from the CTI (i.e., the global scale, absence of emotional coping, and behavioral coping) are all associated negatively with emotional adjustment problems. These associations were re-examined in the present study. More importantly, consistent with the approach adopted by Flett, Hewitt, Blankstein, Solnik, and Van Brunschot (1994), the depression measure was included so that we could examine the link between perfectionism and constructive thinking after removing variance due to depressive symptoms.

\section{METHOD}

\section{Subjects}

A total of 77 students ( 39 men, 38 women) from Ryerson Polytechnic Institute in Toronto, Ontario, participated in the present study.

\section{Measures and Procedure}

The data were collected from February to April, 1993. Subjects were approached randomly in a variety of settings within the institute and asked to take part in a study on personality and adjustment. If subjects agreed to participate, they were administered a questionnaire package consisting of three measures. These measures are described below.

Multidimensional Perfectionism Scale. The MPS (Hewitt \& Flett, 1991b) has 3 subscales of 15 items each. Subjects make seven-point ratings of statements reflecting self-oriented perfectionism (e.g., When 
I am working on something, I cannot relax until it is perfect. One of my goals is to be perfect in everything I do. I must always be successful at school or work), other-oriented perfectionism (e.g., I have high expectations for the people who are important to me. The people who matter to me should never let me down. If I ask someone to do something, I expect it to be done flawlessly), and socially prescribed perfectionism (e.g., My family expects me to be perfect. The better I do, the better I am expected to do. The people around me expect me to succeed at everything I do). Several MPS items are reverse-keyed. With respect to reliability, in 263 psychiatric patients, coefficient alphas were .88 for self-oriented, .74 for other-oriented, and .81 for socially prescribed perfectionism subscales (Hewitt \& Flett, 1991b). Similar reliability estimates have been found in student samples (Hewitt \& Flett, 1991b). Test-retest reliabilities over three months were $.75, .65$, and .78 for the self-oriented, other-oriented, and socially prescribed perfectionism subscales respectively. Factor analyses have confirmed that the MPS consists of three factors (Hewitt \& Flett, 1991b). Initial evidence indicates that the three MPS dimensions are associated significantly with concurrent measures and subscale scores are not influenced unduly by a social desirability response bias (Flett, Hewitt, Blankstein, \& Dynin, 1994; Flett, Hewitt, Blankstein, \& Koledin, 1991; Hewitt, Flett, \& Blankstein, 1991; Hewitt, Flett, Turnbull-Donovan, \& Mikail, 1991).

Constructive Thinking Inventory. The most recent 108-item version of the Constructive Thinking Inventory (CTI; Epstein, 1992c) was used. Epstein and Meier (1989) stated that the CTI was derived by developing test items after reading descriptions of constructive and destructive thinking by famous theorists in the cognitive field, such as Beck (1976), Ellis (1962), and Meichenbaum (1977). The CTI provides overall summary measures of global constructive thinking (e.g., When I am faced with a difficult task, I think encouraging thoughts that help me do my best), lack of emotional coping (e.g., I don't let little things bother me), behavioral coping (e.g., When I realize I have made a mistake, I usually take immediate action to correct it), categorical thinking (e.g., I tend to classify people as either for me or against me), personal superstitious thinking (e.g., If something good happens to me, I tend to assume it was luck), naive optimism (e.g., I believe almost all people are basically good at heart), and esoteric thinking (e.g., I believe some people have the ability to read other people's thoughts). Certain CTI summary scores can also be represented in 
terms of smaller factors. For instance, lack of emotional coping can be broken down into self-acceptance (e.g., I don't feel that I have to perform exceptionally well in order to consider myself a worthwhile person), absence of negative overgeneralization (e.g., reverse keyed; If I do poorly on an important test, I feel like a total failure and that I won't go far in life), non-sensitivity (e.g., I don't let little things bother me), and absence of dwelling (e.g., I tend to dwell more on pleasant than unpleasant incidents from the past). The usefulness of these CTI measures has been demonstrated in various contexts (e.g., Epstein \& Katz, 1992; Hurley, 1990, 1991; Spirrison \& Gordy, 1993).

Beck Depression Inventory. The BDI is a 21-item instrument measuring the behavioral, cognitive, motivational, and vegetative symptoms of depression (Beck et al., 1979). This scale is one of the most widely used measures of the severity of depression symptoms and many studies have demonstrated its reliability and validity (Beck, Steer, \& Garbin, 1988; Bumberry, Oliver, McClure, 1978).

\section{RESULTS}

The correlations between the MPS and CTI dimensions for the total sample are shown in Table 1. In terms of overall CTI subscales, selforiented perfectionism was associated with the presence of behavioral coping, $r=.31, p<.01$. Self-oriented perfectionism was associated positively with the behavioral coping subscales of action orientation, $r=$ $.31, p<.01$, and conscientiousness, $r=.26, p<.05$. Self-oriented perfectionism was not associated with any of the more global CTI subscales, but a strong negative association was obtained between self-oriented perfectionism and self-acceptance thoughts, $r=-.46, p<.01$.

Analyses with other-oriented perfectionism yielded a pattern that was similar to the results obtained with self-oriented perfectionism. In addition to the significant correlations listed above, other-oriented perfectionism was associated with an absence of superstitious thinking, $r=-.26, p<.05$.

As predicted, socially prescribed perfectionism was associated broadly with various CTI measures. As seen in Table 1 , socially prescribed perfectionism was associated with an absence of global constructive thinking, $r=-.41, p<.01$, an absence of positive emotional thinking, $r=-.43, p<.01$, an absence of behavioral coping, $r=$ 


\section{Table 1}

\section{Zero-Order Correlations Between CTI Measures and the Measures of Perfectionism and Depression for the Total Sample}

\begin{tabular}{lcccc}
\hline & \multicolumn{4}{c}{ Measures } \\
CTI Coping Measures & Self & Other & Social & BDI \\
\hline Global Constructive Thinking & .04 & .01 & $-.41^{* *}$ & $-.50^{* *}$ \\
& & & & \\
Positive Emotional Coping & -.20 & -.08 & $-.43^{* *}$ & $-.49^{* *}$ \\
$\quad$ Self-Acceptance & $-.46^{* *}$ & $-.29^{*}$ & $-.34^{* *}$ & $-.27^{* *}$ \\
Lack of Overgeneralization & -.06 & -.02 & $-.36^{* *}$ & $-.41^{* *}$ \\
Non-Sensitivity & -.12 & -.06 & $-.29^{*}$ & $-.37^{* *}$ \\
Absence of Dwelling & -.04 & .09 & $-.39^{* *}$ & $-.52^{* *}$ \\
& & & & \\
Behavioral Coping & $.31^{* *}$ & .21 & $-.29^{* *}$ & $-.36^{* *}$ \\
$\quad$ Positive Thinking & .14 & -.03 & -.16 & -.18 \\
Action Orientation & $.31^{* *}$ & $.26^{*}$ & $-.33^{* *}$ & $-.40^{* *}$ \\
Conscientiousness & $.26^{*}$ & $.24^{*}$ & -.11 & -.20 \\
& & & & \\
Categorical Thinking & .08 & .22 & $.25^{*}$ & $.23^{*}$ \\
$\quad$ Polarized Thinking & .12 & .15 & .07 & .20 \\
Distrust of Others & .12 & .17 & $.25^{*}$ & .12 \\
Intolerance & -.13 & .12 & .15 & .18 \\
& & & & \\
Personal Superstitious Thinking & -.10 & $-.26^{*}$ & $.38^{* *}$ & $.39^{* *}$ \\
& & & & \\
Naive Optimism & .12 & .14 & -.16 & .07 \\
$\quad$ Positive Over-Optimism & .05 & .05 & -.04 & .14 \\
Stereotypical Thinking & -.01 & .17 & $-.26^{*}$ & -.05 \\
Pollyanna-ish Thinking & .19 & .11 & -.11 & .03 \\
Esoteric Thinking & & & & \\
Belief in Unusual & -.05 & -.05 & .16 & $.26^{*}$ \\
Formal Superstitions & -.07 & -.05 & .16 & $.25^{*}$ \\
\hline
\end{tabular}

Note. ${ }^{*} p<.05,{ }^{* *} p<.01$. Based on the responses of 77 subjects. 
$-.29, p<.01$, and the presence of categorical thinking, $r=.25, p<.05$, that was manifested primarily in the form of distrust of others. ${ }^{1}$

Additional analyses confirmed that symptoms of depression are associated broadly with a lack of constructive thinking. The BDI scores were correlated significantly with almost all of the CTI global measures, with naive optimism being the only composite score not linked with symptoms of depression (see Table 1). Surprisingly, analyses with the MPS showed that often obtained association between socially prescribed perfectionism and depressive symptoms was relatively weak in this particular sample and did not attain conventional levels of significance, $r=.16, n s$. Similarly, BDI scores were not correlated significantly with self-oriented perfectionism, $r=-.08$, $n s$, or with other-oriented perfectionism, $r=-.19, n s .^{2}$

\section{Partial Correlations Controlling Depression}

Finally, a series of partial correlations found little evidence that the negative link between perfectionism and constructive thinking was due solely to their mutual association with depression. In the current paper, only the partial correlational analyses with the overall CTI score will be reported rather than the analyses with each of the CTI subscales due to space considerations. Partial correlational analyses controlling for level of depressive symptoms found that self-oriented and other-oriented perfectionism were not associated with constructive thinking; however, consistent with the zero-order correlations, socially prescribed perfectionism was still associated with an absence of constructive thinking, $r=-.39, p<.001$, after controlling variance associated with depressive symptoms.

\section{DISCUSSION}

The present study further investigated the association among perfectionism, coping tendencies, and depressive symptoms. A sample of

\footnotetext{
${ }^{1}$ Separate correlational analyses are not reported for men and women because the results tended to be similar. For instance, global constructive thinking was linked with socially prescribed perfectionism among men, $r=-.36, p<.05$, and among women, $r=-.46, p<.01$, and the other perfectionism dimensions were not related significantly to global constructive thinking.

${ }^{2}$ It should be noted that partial correlational analyses that controlled self-oriented and otheroriented perfectionism did establish a link between socially prescribed perfectionism and depression symptoms.
} 
college students completed the MPS, the CTI, and a measure of depressive symptoms. Correlational analyses confirmed past indications that self-oriented perfectionism has some positive and negative coping features, while socially prescribed perfectionism is associated broadly with negative indices of coping. Self-oriented perfectionists reported higher levels of positive behavioral coping in the form of greater conscientiousness and action-orientation. However, this was offset by a relative absence of positive emotional coping due to a marked lack of self-acceptance on the part of self-oriented perfectionists. In many respects, the CTI self-acceptance scale item content captures the allor-none thinking orientation that is believed to characterize the perfectionist's inability to tolerate failure. It has items such as "I take failure very hard" and "I feel like a total failure if I don't achieve the goals I set for myself." In many circumstances, it is quite possible that this extreme response to failure may overwhelm the self-oriented perfectionist's desire or ability to engage in positive forms of behavioral coping that reflect conscientiousness and action orientation. Overall, however, it is important to keep in mind the results of the present study which showed that self-oriented perfectionism was associated with only one negative aspect, and it was unrelated to the overall measure of global constructive thinking.

In contrast, analyses with socially prescribed perfectionism indicated that this MPS subscale was associated negatively with a global measure of constructive thinking, and examination of the CTI subscales confirmed the presence of a pervasive link between socially prescribed perfectionism and negative coping responses. Socially prescribed perfectionism was associated with an absence of positive emotional coping and an absence of behavioral coping, along with a tendency to manifest categorical and superstitious thinking. Examination of the CTI subscales that comprise the emotional coping dimension confirmed many previous observations about perfectionism in that socially prescribed perfectionists were high in the reported tendency to overgeneralize negative outcomes and cognitively dwell on negative outcomes. The tendency to fret and ruminate about negative outcomes is consistent with earlier reports which indicated that the thinking patterns of perfectionists are dominated by images and fears involving the possibility of making mistakes (Frost \& Henderson, 1991). According to our current findings, this tendency to mentally rehearse failures and think about unpleasant events is accompanied by low self-acceptance and a tendency to overgeneralize. The link between socially prescribed perfectionism and overgeneralization repli- 
cates past findings in this area (Hewitt, Flett, Turnbull-Donovan, \& Mikail, 1991).

The differences between socially prescribed perfectionism and selforiented perfectionism are most clearly illustrated by the results obtained with the behavioral coping measure. While self-oriented perfectionism was associated positively with behavioral coping, socially prescribed perfectionism was associated negatively with behavioral coping. In particular, self-oriented perfectionists had a high level of action orientation, while socially prescribed perfectionists had a relative absence of action orientation. In addition, the subjects with a high level of socially prescribed perfectionism manifested a form of personally superstitious and categorical thinking that reflected a pessimistic tendency to believe that good outcomes will necessarily be followed by bad outcomes, and other people cannot be trusted.

Additional analyses with the BDI confirmed that higher depressive symptoms are associated with an absence of constructive thinking, consistent with earlier research by Epstein and colleagues. Analyses involving the broad CTI dimensions showed that students with higher levels of depressive symptoms reported lower overall levels of constructive thinking, a tendency to engage in emotional coping, and a relative absence of behavioral coping. These findings closely replicated those obtained in past research with the CTI and they accord with general reports of a link between depressive symptoms and a coping style characterized by high levels of emotion-oriented coping and behavioral avoidance of problem-solving (e.g., Billings \& Moos, 1984; Endler \& Parker, 1990; Folkman, Lazarus, Gruen, \& Delongis, 1986).

The results involving CTI and BDI scores quite closely paralleled the findings with socially prescribed perfectionism in that both socially prescribed perfectionism and elevated depressive symptoms were associated with lower levels of positive emotional and behavioral coping, and higher levels of superstitious and categorical thinking. Given these similarities, it was important to establish with the partial correlational analyses that the link between socially prescribed perfectionism and nonconstructive thinking was still present after removing variance associated with depressive symptomatology. Thus, the findings with perfectionism cannot be attributed solely to the mutual overlap that perfectionism and maladaptive thinking have with psychological distress.

Overall, the findings with socially prescribed perfectionism are potentially important because the data suggest that perfectionism is not only associated with vulnerability to depression, it is also associated 
with the coping process. Historically, research on personality, stress, and depression has proceeded without much consideration of the possibility that various personality factors are associated differentially with particular coping styles and related cognitive appraisals. In addition to examining the association among personality, stress, and depression, it is important to examine the coping responses and resources associated with such traits as perfectionism. Transactional models of coping such as those proposed by Lazarus and Folkman (1984) as well as by Moos and Schaefer (1993) suggest that it is important to include a focus on the coping resources and cognitive appraisals that are available to individuals when confronted with a stressful situation. This approach recognizes that the identical stressor will vary in its impact on individuals depending on the individuals' cognitive appraisals of the stressor and the availability of adaptive coping responses. The present findings signify that socially prescribed perfectionists will not react well when presented with difficult and stressful circumstances, and this personal lack of appropriate coping responses and the tendency to experience maladaptive cognitions may serve to prolong and exacerbate the initial distress.

The results of the current study suggest the need for future research on perfectionism and the presence or absence of constructive thinking. One important direction for future research involves the issue of whether certain forms of constructive thinking moderate the link between perfectionism and depression. Research that tests this possibility would be in keeping with a wealth of recent evidence which suggests that numerous factors influence the link between perfectionism and maladjustment, including major life events stress, daily hassles, and levels of self-control (Flett, Hewitt, \& Dyck, 1989; Flett, Hewitt, Blankstein, \& Mosher, 1991; Flett, Hewitt, Blankstein, \& O'Brien, 1991; Hewitt \& Flett, 1993; Hewitt \& Dyck, 1986; Hewitt et al., in press; Mor, Day, Flett, \& Hewitt, in press). A related area for further investigation involves the cognitive operations engaged in by perfectionists. Future research in our laboratory will investigate whether perfectionists and nonperfectionists can be differentiated in terms of the cognitive tendencies that they exhibit in a controlled situation. A particular focus of this research will be to determine how perfectionists react cognitively when confronted with ego-involving stressors that connote failure. Perhaps a stronger association between self-oriented perfectionism and maladaptive cognitive reactions will be detectable in this type of situation.

In summary, the results of this correlational study confirmed that 
dimensions of perfectionism are associated with maladaptive coping styles, and there are indications that perfectionism is associated with maladaptive forms of thinking. Consistent with earlier research on perfectionism and indices of maladjustment, socially prescribed perfectionism was the MPS dimension that was most consistently linked with maladaptive coping responses and a relative absence of constructive thinking. At a practical level, these findings are in accordance with previous suggestions (e.g., Barrow \& Moore, 1983; Moore \& Barrow, 1986) that perfectionists are especially likely to benefit from cognitive restructuring interventions and cognitive-behavioral techniques that are designed to facilitate the development of appropriate forms of problem-focused coping.

\section{REFERENCES}

Barrow, J. C., \& Moore, C. A. (1983). Group interventions with perfectionistic thinking. Personnel and Guidance Journal, 61, 612-615.

Beck, A. T. (1976). Cognitive therapy and the emotional disorders. New York: International University Press.

Beck, A. T., Rush, A. J., Shaw, B. F., \& Emery, G. (1979). Cognitive therapy of depression: A treatment manual. New York: Guilford.

Beck, A. T., Steer, R. A., \& Garbin, M. G. (1988). Psychometric properties of the Beck Depression Inventory: Twenty-five years of evaluation. Clinical Psychology Review, 8, 77-100.

Billings, A. G., \& Moos, R. H. (1984). Coping, stress, and social resources among adults with unipolar depression. Journal of Personality and Social Psychology, 46, 877-891.

Bumberry, W., Oliver, J. M., \& McClure, J. N. (1978). Validation of the Beck Depression Inventory in a university population using psychiatric estimate as the criterion. Journal of Consulting and Clinical Psychology, 46, $150-155$.

Burns, D. D. (1980). Feeling good: The new mood therapy. New York: New American Library.

Burns, D. D., \& Beck, A. T. (1978). Cognitive behavior modification of mood disorders. In J. P. Foreyt and D. P. Rathjen (Eds.), Cognitive behavior (pp. 109-134). New York: Plenum.

Dweck, C. S. (1986). Motivational processes affecting learning. American Psychologist, 41, 1040-1048.

Dweck, C. S., \& Elliott, E. S. (1983). Achievement motivation. In E. M. Hetherington (Ed.), Socialization, personality, and social development (pp. 643-691). New York: Wiley.

Dweck, C. S., \& Leggett, E. L. (1988). A social-cognitive approach to motivation and personality. Psychological Review, 95, 256-273.

Elliott, E. S., \& Dweck, C. S. (1988). Goals: An approach to motivation and attachment. Journal of Personality and Social Psychology, 54, 5-12. 
Ellis, A. (1962). Reason and emotion in psychotherapy. New York: Lyle Stewart.

Endler, N. S., \& Parker, J. D. A. (1990). Multidimensional assessment of coping: A critical evaluation. Journal of Personality and Social Psychology, 58, 844-854.

Epstein, S. (1992a). Constructive thinking and mental and physical well-being. In L. Montada, S. Filipp, \& M. J. Lerner (Eds.), Life crises and experiences of loss in adulthood (pp. 385-409). Hillsdale, NJ: Erlbaum.

Epstein, S. (1992b). Coping ability, negative self-evaluation, and overgeneralization: Experiment and theory. Journal of Personality and Social Psychology, 62, 826-836.

Epstein, S. (1992c). CTI (108-item version) scoring key. Unpublished document.

Epstein, S., \& Katz, L. (1992). Coping ability, stress, productive load, and symptoms. Journal of Personality and Social Psychology, 62, 813-825.

Epstein, S., \& Meier, P. (1989). Constructive thinking: A broad coping variable with specific components. Journal of Personality and Social Psychology, 57, 332-350.

Flett, G. L., Hewitt, P. L., Blankstein, K. R., \& Dynin, C. (1994). Dimensions of perfectionism and Type A behaviour. Personality and Individual Differences, 16, 477-485.

Flett, G. L., Hewitt, P. L., Blankstein, K. R., \& Koledin, S. (1991). Dimensions of perfectionism and irrational thinking. Journal of Rational-Emotive and Cognitive-Behavior Therapy, 9, 185-201.

Flett, G. L., Hewitt, P. L., Blankstein, K. R., \& Mosher, S. W. (1991). Perfectionism, self-actualization, and personal adjustment. Journal of Social Behavior and Personality, 6, 147-160.

Flett, G. L., Hewitt, P. L., Blankstein, K. R., \& O'Brien, S. (1991). Perfectionism and learned resourcefulness in depression and self-esteem. Personality and Individual Differences, 12, 61-68.

Flett, G. L., Hewitt, P. L., Blankstein, K. R., Solnik, M., \& Van Brunschot, M. (1994). Perfectionism and social problem-solving ability. Manuscript submitted for publication.

Flett, G. L., Hewitt, P. L., Boucher, D. J., Davidson, L. A., \& Munro, Y. (1992). The Child-Adolescent Perfectionism Scale: Development, validation, and association with adjustment. York University Psychology Department Report No. 203, North York, Ontario, Canada.

Flett, G. L., Hewitt, P. L., \& Dyck, D. G. (1989). Self-oriented perfectionism, neuroticism, and anxiety. Personality and Individual Differences, 10, 731-735.

Flett, G. L., Hewitt, P. L., McGregor-Temple, T., \& Pickering, D. (1994). Motivational orientations and dimensions of perfectionism. Manuscript submitted for publication.

Folkman, S., Lazarus, R. S., Gruen, R., \& Delongis, A. (1986). Appraisal, coping, health status, and psychological symptoms. Journal of Personality and Social Psychology, 50, 571-579.

Frost, R. O., Heimberg, R., Holt, C., Mattia, J., \& Neubauer, A. (1993). A comparison of two measures of perfectionism. Personality and Individual Differences, 14, 119-126. 
Frost, R. O., \& Henderson, H. J. (1991). Perfectionism and reactions to athletic competition. Journal of Sport and Exercise Psychology, 13, 323-335.

Frost, R. O., Marten, P. A., Lahart, C., \& Rosenblate, R. (1990). The dimensions of perfectionism. Cognitive Therapy and Research, 14, 449-468.

Frost, R. O., \& Shows, D. L. (1993). The nature and measurement of compulsive indecisiveness. Behaviour Research and Therapy, 31, 683-692.

Hamachek, D. E. (1978). Psychodynamics of normal and neurotic perfectionism. Psychology, 15, 27-33.

Hewitt, P. L., \& Dyck, D. G. (1986). Perfectionism, stress, and vulnerability to depression. Cognitive Therapy and Research, 10, 137-142.

Hewitt, P. L., \& Flett, G. L. (1990). Dimensions of perfectionism and depression: A multidimensional analysis. Journal of Social Behavior and Personality, 5, 423-438.

Hewitt, P. L., \& Flett, G. L. (1991a). Dimensions of perfectionism in unipolar depression. Journal of Abnormal Psychology, 100, 98-101.

Hewitt, P. L., \& Flett, G. L. (1991b)- Perfectionism in the self and social contexts: Conceptualization, assessment, and association with psychopathology. Journal of Personality and Social Psychology, 60, 456-470.

Hewitt, P. L., \& Flett, G. L. (1993a). Dimensions of perfectionism, daily stress, and depression: A test of the specific vulnerability hypothesis. Journal of Abnormal Psychology, 102, 58-65.

Hewitt, P. L., \& Flett, G. L. (1993b). Perfectionism and goal orientation in impulsive and suicidal behavior. In W. McCown, M. Shure, \& J. Johnson (Eds.), The impulsive client: Theory, research, and treatment (pp. 247263). Arlington, VA: American Psychological Association Press.

Hewitt, P. L., \& Flett, G. L. (in press). Personality traits and the coping process. In M. Zeidner and N. S. Endler (Eds.), Handbook of coping. London: Wiley.

Hewitt, P. L., Flett, G. L., \& Blankstein, K. R. (1991). Perfectionism and neuroticism in psychiatric patients and college students. Personality and Individual Differences, 12, 273-279.

Hewitt, P. L., Flett, G. L., \& Endler, N. S. (in press). Perfectionism, coping, and depression symptomatology in a clinical sample. Clinical Psychology and Psychotherapy.

Hewitt, P. L., Flett, G. L., \& Turnbull-Donovan, W. (1992). Perfectionism and suicide potential. British Journal of Clinical Psychology, 31, 181-190.

Hewitt, P. L., Flett, G. L., Turnbull-Donovan, W., \& Mikail, S. (1991). The Multidimensional Perfectionism Scale: Reliability, validity, and psychometric properties in psychiatric samples. Psychological Assessment: A Journal of Consulting and Clinical Psychology, 3, 464-468.

Hewitt, P. L., Flett, G. L., \& Weber, C. (in press). Perfectionism, hopelessness, and suicide ideation. Cognitive Therapy and Research.

Hewitt, P. L., \& Genest, M. (1990). The ideal-self: Schematic processing of perfectionistic content in dysphoric university students. Journal of Personality and Social Psychology, 59, 802-808.

Hewitt, P. L., Mittelstaedt, W., \& Wollert, R. (1989). Validation of a measure of perfectionism. Journal of Personality Assessment, 53, 133-144.

Hollender, M. H. (1965). Perfectionism. Comprehensive Psychiatry, 6, 94-103. 
Hurley, J. R. (1990). Constructive thinking and elevated levels of self in interpersonal groups. Journal of Psychology, 124, 563-573.

Hurley, J. R. (1991). Related measures of constructive and rational thinking. Journal of Psychology, 125, 229-235.

Katz, L., \& Epstein, S. (1991). Constructive thinking and coping with laboratory-induced stress. Journal of Personality and Social Psychology, 61, 789- 800 .

Lazarus, R. S., \& Folkman, S. (1984). Stress, appraisal, and coping. New York: Springer.

Meichenbaum, D. (1977). Cognitive behavior modification. New York: Plenum Press.

Missildine, W. H. (1963). Your inner child of the past. New York: Simon \& Schuster.

Moore, C. A., \& Barrow, J. C. (1986). Perfectionistic thinking in university students: Implications for individual treatment. In J. E. Talley \& W. J. K. Rockwell (Eds.), Counseling and psychotherapy with college students (pp. 100-112). New York: Praeger.

Moos, R. H., \& Schaefer, J. A. (1993). Coping resources and processes: Current concepts and measures. In L. Goldberger \& S. Breznitz (Eds.), Handbook of stress: Theoretical and clinical aspects, 2nd ed. (pp. 234-257). New York: The Free Press.

Mor, S., Day, H. I., Flett, G. L., \& Hewitt, P. L. (in press). Perfectionism, control, and components of performance anxiety in professional performers. Cognitive Therapy and Research.

Pacht, A. R. (1984). Reflections on perfection. American Psychologist, 39, 386-390.

Pirot, M. (1986). The pathological thought and dynamics of the perfectionist. Individual Psychology, 42, 51-58.

Rickner, R. G., \& Tan, S-Y. (1994). Psychopathology, guilt, perfectionism, and family of origin functioning among protestant clergy. Journal of Psychology and Theology, 22, 29-38.

Spirrison, C. L., \& Gordy, C. C. (1993). The Constructive Thinking Inventory and detecting errors in proofreading. Perceptual and Motor Skills, 76, 631-634. 